\title{
Questions of Time and Affect: A person's affectivity profile, time perspective, and well-being
}

Danilo Garcia, Uta Sailer, Ali Al Nima, Trevor Archer

Background: A "balanced" time perspective has been suggested to have a positive influence on well-being: a sentimental and positive view of the past (high Past Positive), a less pessimistic attitude toward the past (low Past Negative), the desire of experiencing pleasure with slight concern for future consequences (high Present Hedonistic), a less fatalistic and hopeless view of the future (low Present Fatalistic), and the ability to find reward in achieving specific long-term goals (high Future). We used the affective profiles model (i.e., combinations of individuals' experience of high/low positive/negative affectivity) to investigate differences between individuals in time perspective dimensions and to investigate if the influence of time perspective dimensions on well-being was moderated by the individual's type of profile.

Method: Participants $(N=720)$ answered to the Positive Affect Negative Affect Schedule, the Zimbardo Time Perspective Inventory and two measures of well-being: the Temporal Satisfaction With Life Scale and Ryff's Scales of Psychological Well-Being-short version. A Multivariate Analysis of Variance (MANOVA) was conducted to identify differences in time perspective dimensions and well-being among individuals with distinct affective profiles. Four Structural Equation Models (SEM) were used to investigate which time perspective dimensions predicted well-being for individuals in each profile.

Results: Comparisons between individuals at the extreme of the affective profiles model suggested that individuals with a self-fulfilling profile (high positive/low negative affect) were characterized by a "balanced" time perspective and higher well-being compared to individuals with a self-destructive profile (low positive/high negative affect). However, a different pattern emerged when individuals who differed in one affect dimension but matched in the other were compared to each other. For instance, decreases in the past negative time perspective dimension lead to high positive affect when negative affect is high (i.e., self-destructive vs. high affective) but to low negative affect when positive affect was high (i.e., high affective vs. self-fulfilling). The moderation analyses showed, for example, that for individuals with a self-destructive profile, psychological well-being was 
significantly predicted by the past negative, present fatalistic and future time perspectives. Among individuals with a high affective or a self-fulfilling profile, psychological well-being was significantly predicted by the present fatalistic dimension.

Conclusions: The interactions found here go beyond the postulation of a "balanced" time perspective being the only way of promoting well-being. Instead, we present a more person-centered approach to achieve higher levels of emotional, cognitive, and psychological well-being. 
Questions of Time and Affect:

\section{A person's affectivity profile, time perspective, and well-being}


26

27

28

29

30

31

32

33

34

35

36

37

38

39

40

41

42

43

44

45

46

47

48

49

50

51

52

53

54

55

56

57

58

59

60

61

62

63

64

65

66

67

68

69

\begin{abstract}
Background: A "balanced" time perspective has been suggested to have a positive influence on well-being: a sentimental and positive view of the past (high Past Positive), a less pessimistic attitude toward the past (low Past Negative), the desire of experiencing pleasure with slight concern for future consequences (high Present Hedonistic), a less fatalistic and hopeless view of the future (low Present Fatalistic), and the ability to find reward in achieving specific long-term goals (high Future). We used the affective profiles model (i.e., combinations of individuals' experience of high/low positive/negative affectivity) to investigate differences between individuals in time perspective dimensions and to investigate if the influence of time perspective dimensions on well-being was moderated by the individual's type of profile.
\end{abstract}

Method: Participants $(N=720)$ answered to the Positive Affect Negative Affect Schedule, the Zimbardo Time Perspective Inventory and two measures of well-being: the Temporal Satisfaction With Life Scale and Ryff's Scales of Psychological Well-Being-short version. A Multivariate Analysis of Variance (MANOVA) was conducted to identify differences in time perspective dimensions and well-being among individuals with distinct affective profiles. Four Structural Equation Models (SEM) were used to investigate which time perspective dimensions predicted well-being for individuals in each profile.

Results: Comparisons between individuals at the extreme of the affective profiles model suggested that individuals with a self-fulfilling profile (high positive/low negative affect) were characterized by a "balanced" time perspective and higher well-being compared to individuals with a self-destructive profile (low positive/high negative affect). However, a different pattern emerged when individuals who differed in one affect dimension but matched in the other were compared to each other. For instance, decreases in the past negative time perspective dimension lead to high positive affect when negative affect is high (i.e., self-destructive vs. high affective) but to low negative affect when positive affect was high (i.e., high affective vs. self-fulfilling). The moderation analyses showed, for example, that for individuals with a self-destructive profile, psychological well-being was significantly predicted by the past negative, present fatalistic and future time perspectives. Among individuals with a high affective or a selffulfilling profile, psychological well-being was significantly predicted by the present fatalistic dimension.

Conclusions: The interactions found here go beyond the postulation of a "balanced" time perspective being the only way of promoting well-being. Instead, we present a more personcentered approach to achieve higher levels of emotional, cognitive, and psychological wellbeing. 
70

71

72

73

74

75

76

77

78

79

80

81

82

83

84

85

86

87

88

89

90

91

92

93

94

"When I was a boy, what joy

playing war night and day

jumping over a fence to see you

and like that discover something new in your eyes"

From the song "El gato que esta triste y azul" [The Cat Who Is Sad and Blue] performed by Roberto Carlos and written by Giancarlo Bigazzi and Toto Savio.

According to Zimbardo and Boyd (1999; 1271), time perspective is the process of assigning experiences "to temporal categories, or time frames, that help to give order, coherence, and meaning to those events." The mental organization of time is typically anchored in the time referents of past, present, and future (Shmotkin \& Eyal 2003). The way in which an individual evaluates each of these constitutes her/his time perspective, or time orientation (Wallace \& Rabin 1960). According to time perspective theory, the way individuals view their past, present, and future influences their decisions and behavior.

One of the most widely used measures of time perspective is the Zimbardo Time Perspective Inventory (ZTPI; Zimbardo \& Boyd, 1999). The ZTPI measures five time dimensions: 1) Past-Positive, a nostalgic, positive attitude towards the past that is positively related to high self-esteem and happiness; 2) Past-Negative, a generally negative view of the past that is positively related to depression, low self-esteem, anxiety, sadness and aggression; 3) Present-Hedonistic, a hedonistic, enjoyment- and pleasure-oriented attitude towards time without worrying about the future associated to low need for predictability, poor impulse control and 
95 increased novelty seeking; 4) Present-Fatalistic, a fatalistic, helpless, and hopeless attitude 96 toward the future and life that is related to aggression, anxiety, and depression; and 5) Future, an

97 orientation that includes the planning for and achievement of future goals and the tendency to 98 postpone direct gratification in favor of long-term goals (Zimbardo \& Boyd 1999). Time perspective has also been found to influence cognitive well-being, that is, an individual's own evaluation of her/his life satisfaction (Diener, 1984). Whereas no single time perspective in itself fosters life satisfaction, it is predicted by a "balanced" time perspective: high values on past positive, present hedonistic and future perspectives, and low values on past negative and present fatalistic perspectives (Boniwell et al. 2010). Moreover, personal characteristics that allow the individual to adapt and flourish in life (i.e., psychological well-being; Ryff, 1989) seem to also be related to the same pattern of "balanced" time perspective (Sailer et al., 2014). Nevertheless, well-being has been suggested to be a result of a complex interaction of a person's affective, cognitive, and social characteristics (Cloninger, 2004).

In accordance with such complex patterns between and within individuals, a correlational study found different patterns of time perspective to be associated to positive and negative affect ${ }^{1}$.

110 Positive affect was positively related to the present hedonistic and future time perspective, but negatively related to the past negative and present fatalistic time dimensions (Sailer et al., 2014).

112 Negative affect on the other hand was positively related to the past negative and present fatalistic 113 time perspective dimensions and negatively related to the present hedonistic time perspective 114 dimension (Sailer et al., 2014). Although these results give an indication on the association 115 between individuals' time perspective and affectivity, the affective system is often described as a

${ }^{1}$ Positive affect is a dimension that varies from pleasant engagement (e.g., enthusiastic and active) to unpleasant disengagement (e.g., sad and bored). The negative affect dimension, on the other hand, moves from unpleasant engagement (e.g., anger and fear) to pleasant disengagement (e.g. calm and serene) (Watson \& Clark, 1994; Watson, Clark \& Tellegen, 1988). 
116 complex dynamic system composed of these two affectivity dimensions (i.e., positive affect and

117 negative affect), which are independent of each other and regulate our approach and withdrawal

118 behavior towards stimuli (e.g., Watson, Clark \& Tellegen, 1988). Individuals characterized by

119 high levels of positive affect exhibit a greater appreciation of life, more security, self-esteem and 120 self-confidence (Archer et al., 2008; Costa and McCrae, 1980; Varg, 1997); they enjoy more

121 social relations and assertiveness and are generally described as passionate, happy, energetic and 122 alert (Watson \& Clark, 1984; Watson \& Pennebaker, 1989). In contrast, individuals 123 characterized by high levels of negative affect experience greater stress and strain, anxiety and 124 uncertainty over a wide range of circumstances and events over which they generally lack control (Watson et al., 1986). The two affectivity dimensions are not only related to different

126 behavior but also are probably influenced by the environment to different extent and have 127 different genetic etiology (see Cloninger \& Garcia, 2015). The independent inter-relationship of 128 these two affectivity dimensions also implies that individuals do not only differ in affectivity 129 between each other but also within themselves (Garcia, 2011; Garcia, Garcia, Adrianson, Archer \& Rosenberg, 2015). If so, individuals might differ in the way they perceive time depending on their affective profile (i.e., different combinations of high/low positive/negative affect) and what is more, the way in which time perspective is related to well-being might be moderated by the individuals' own affective profile. Bood \& Archer, 2002) conceptualized how individuals' differ, between and within, in levels of affectivity by incorporating different combinations of individuals' recalled experience of positive and negative affect, resulting in different "affective profiles": (i) high positive affect and low 138 negative affect, characterizing a "self-fulfilling" profile, (ii) high positive affect and high 
139 negative affect, characterizing a "high affective" profile, (iii) low positive affect and low

140 negative affect, characterizing a "low affective" profile, and (iv) low positive affect and high

141 negative affect, characterizing a "self-destructive" profile. Individuals with high negative affect,

142 particularly those with a self-destructive profile compared to individuals with a self-fulfilling

143 profile, report lower well-being, higher psychological and somatic stress, low energy, lack of

144 dispositional optimism, heightened pessimism, high levels of non-constructive perfectionism,

145 depression and anxiety, lower levels of constructive coping and higher levels of maladaptive

146 coping, total stress at the work-place, more Type A behavior, lack of emotional stability and

147 partner relationships, and high levels of external locus of control and impulsiveness (e.g.,

148 Andersson-Arntén, 2009; Garcia, 2011; 2012; Schütz, 2015; Norlander et al., 2002, 2005; Bood

149 et al., 2004). Thus, individuals with a self-destructive profile can be expected to have a less

150 "balanced" time perspective compared to individuals with any of the other profiles.

151 The affective profiles model allows the comparison between individuals who differ in

152 their level of experienced affect in both dimensions, but also the comparison of individuals who

153 match each other in one dimension and differ in their experience in the other affect dimension

154 (i.e., allowing a within-individual comparison). For example, when individuals with a low

155 affective profile are compared to their diametric opposites (i.e., individuals with a high affective

156 profile), they show higher levels of somatic stress when doing a stressful task (Norlander et al.,

157 2005). This may be because, in contrast to individuals with a low affective profile, individuals

158 with a high affective profile experience high positive affect, which may neutralize their

159 experience of high negative affect and therefore, reduce stress (Fredrickson, 2006; Garcia \&

160 Siddiqui, 2009a). Nevertheless, individuals with any of these two profiles do not differ in life

161 satisfaction between each other (Garcia \& Siddiqui, 2009ab). This suggests that for individuals 
162 with a low affective profile, low levels of stress and high levels of life satisfaction are linked to

163 their experience of low negative affect, while for individuals with a high affective profile this

164 very same experience (i.e., low stress and high life satisfaction) is linked to high levels of 165 positive affect (cf. Garcia, 2011; Schütz, 2015).

In addition, when individuals with a low affective profile are compared to individuals to

167

168

169

170

171

172

173

174

175

176

177

178

179

180

181

182

183

184

whom they only partially differ in affectivity levels (i.e., self-destructive and self-fulfilling), individuals with a low affective profile report higher life satisfaction than individuals with a selfdestructive profile and equally high levels of life satisfaction and equally low levels of stress as individuals with a self-fulfilling profile (Garcia, 2011). In other words, although both of these profiles (i.e., low affective and self-destructive) are characterized by low levels of positive affect, individuals with a low affective profile (low positive affect/low negative affect) are more satisfied with their life than individuals with a self-destructive profile (low positive affect/ high negative affect). Individuals with a low affective profile (low positive affect/low negative affect) are also as satisfied with their life as individuals with a self-fulfilling profile (high positive affect/low negative affect), although the latter experience more positive affect.

In sum, depending on their profile, individuals are able to regulate their well-being, probably by specific strategies that fit their profile to maintain homeostasis in their affective system (cf. Garcia, Rosenberg, Erlandsson \& Siddiqui, 2010). If so, different time perspectives might influence individuals' life satisfaction and psychological well-being depending on their affective profile. The present study investigated differences in time perspective and well-being between individuals with distinct affective profiles. We expected individuals with a self-fulfilling profile to be more "balanced" in their time perspective: more positive and less negative about their past, more hedonistic and less fatalistic about their present, and more future oriented. We 
185 also addressed the question whether or not the effect of the time perspective dimensions on 186 psychological well-being and life satisfaction is moderated by the individual's type of profile.

187

188

189

190

191

192

193

194 195

196

197

198

199

200

201

202

203

204

205

206

207

\section{Method}

\section{Ethical statement}

After consulting with the Network for Empowerment and Well-Being's Review Board we arrived at the conclusion that the design of the present study (e.g., all participants' data were anonymous and will not be used for commercial or other non-scientific purposes) required only informed consent from the participants.

\section{Participants and procedure}

The present study was based on a sample of 720 participants with an age mean of $25.25 \pm 11.73$ (males $=247$, females $=473$, and 7 participants who didn't report their gender). They were students at one University and pupils at two high schools in the West of Sweden. All participants were informed that their participation was voluntary and anonymous. They were presented with a battery of instruments used to collect the relevant measures in the following order: background, time perspective, temporal satisfaction with life, psychological well-being, and affect.

\section{Measures}

Affect. The Positive Affect and Negative Affect Schedule (Watson, Clark \& Tellegen, 1988) assesses the affective component of subjective well-being by requiring participants to rate to what extent $(1=$ very slightly, $5=$ extremely $)$ during the last few weeks they have experienced 10 positive and 10 negative affective states. The positive affect scale includes adjectives such as strong, proud, and interested; and the negative affect scale includes adjectives such as afraid, ashamed, and nervous. The Swedish version has been used in previous studies with good psychometric properties (Cronbach's $\alpha$ between .88-.90; e.g., Garcia, Nima\& Kjell, 2014; Nima, 
208 Archer \& Garcia, 2012, 2013; Nima, Rosenberg, Archer \& Garcia, 2013; Schütz, Archer \&

209 Garcia, 2013). Cronbach's $\alpha$ in the present study was .86 for positive affect and .85 for negative 210 affect.

211 Time Perspective. The Zimbardo Time Perspective Inventory (Zimbardo\& Boyd, 1999)

212 consists of 56 items that measure the following five time dimensions: Past Positive (e.g., "It

213 gives me pleasure to think about my past"), Past Negative (e.g., "I think about the good things

214 that I have missed out on in my life”), Present Hedonistic (e.g., "Taking risks keeps my life from

215 becoming boring"), Present Fatalistic (e.g., "Fate determines much in my life"), and Future (e.g.,

216 "I believe that a person's day should be planned ahead each morning"). The Swedish version has

217 been used in previous studies and showed good psychometric properties (Cronbach's $\alpha$ between

218 .68-.87; e.g., Sailer, Rosenberg, Nima, Gamble, Gärling, Archer \& Garcia, 2014) and its

219 psychometric properties have been validated in many different languages (Milfont, Andrade,

220 Belo \& Pessoa, 2008; Liniauskaite \& Kairys, 2009; Díaz-Morales, 2006). Cronbach's $\alpha$ in the

221 present study was .72 for Past Positive, .85 for Past Negative, .76 for Present Hedonistic, .63 for

222 Present Fatalistic, and .70 for Future.

223 Temporal Life Satisfaction. The Temporal Satisfaction With Life Scale (Pavot, Diener \& 224 Suh, 1998) comprises 15-items rated on a 7-point Likert scale $(1=$ strongly disagree, $7=$ 225 strongly agree) assessing past (e.g., "If I had my past to live over, I would change nothing"), 226 present (e.g., "I would change nothing about my current life"), and future life satisfaction (e.g., 227 "There will be nothing that I will want to change about my future"). The Swedish version of the 228 instrument has been used in previous studies (Cronbach's $\alpha$ between .88-.93; Sailer et al., 2014; 229 Garcia, Rosenberg \& Siddiqui, 2011). Cronbach's $\alpha$ in the present study was .92 for the whole 230 scale. 
232 Marshall, Ryff \& Wheaton, 2001) comprises 18 items including 3 items for each of the six

233 dimensions. These dimensions are: self-acceptance (e.g., "I like most aspects of my

234 personality"), personal growth (e.g., "For me, life has been a continuous process of learning,

235 changing, and growth"), purpose in life ("Some people wander aimlessly through life, but I am

236 not one of them"), environmental mastery (e.g., "I am quite good at managing the responsibilities

237 of my daily life"), autonomy (e.g., "I have confidence in my own opinions, even if they are

238 contrary to the general consensus"), and positive relations with others (e.g., "People would

239 describe me as a giving person, willing to share my time with others"). The Swedish version has

240 been used in previous studies (e.g., Garcia, 2011, 2013). Since the subscales have been found to

241 have low reliability, the total psychological well-being score (i.e., the sum of the 18 items) is

242 recommended as a better and more reliable measure (Garcia \& Siddiqui, 2009b). A Cronbach's $\alpha$

243 of .78 was obtained for the total psychological well-being score in the present study.

244 Statistical treatment

245 The affective profiles were created by dividing self-reported positive affect and negative affect

246 scores into high and low using a median split (Norlander, Bood \& Archer, 2002). This resulted

247 in the following affective profiles: 222 "self-destructive" (low positive and high negative affect),

248131 "low affective" (low positive and low negative affect), 150 "high affective" (high positive

249 and high negative affect) and 217 "self-fulfilling" (high positive and low negative affect).

250 Missing data. The majority of missing data was found to be missing completely at

251 random using Little's Chi-Square test; $\left(\chi 2=30.10(d f=28, p=.36)\right.$ for self-destructive men, $\chi^{2}$

$252=17.54(d f=9, p=.04)$ for low affective men, $\chi 2=26.79(d f=20, p=.14)$ for high affective

253 men, $\chi^{2}=17.61(d f=15, p=.28)$ for self-fulfilling men, $\chi^{2}=37.87(d f=37, p=.43)$ for self- 
254 destructive women, $\chi^{2}=22.69(d f=26, p=.65)$ for low affective women, $\chi^{2}=26.14(d f=27, p$

$255=.51)$ for high affective women and $\chi^{2}=57.24(d f=28, p=.001)$ for self-fulfilling women. The

256 Expectation-Maximization Algorithm ${ }^{2}$ was used to replace missing values.

257 Normality of sampling distributions of means. Our sample size of 720 participants

258 included over 20 cases for each cell. Therefore, we anticipated normality of sampling

259 distributions of means. Indeed, according to the Central Limit Theorem, with sufficiently large

260 sample sizes, sampling distributions of means are normally distributed regardless of the

261 distributions of variables. (see Tabachnick \& Fidell, 2007, p.78). In other words, our data met the

262 assumptions necessary to conduct a MANOVA.

Univariate outliers and normality. In order to determine and reduce the impact of

variables with univariate outliers within the affective profiles we first standardized the scores by negative, 1 in present fatalistic and 2 in future (i.e., standardized scores larger than \pm 3.29 ). These outlier scores were changed to the next highest non-outlier score +1 , as described by Tabachnick and Fidell (2007, p 77).

2 The Expectation-Maximization Algorithm is one of the most common algorithms to estimate the parameters (e.g., means and standard deviations) of a statistical model given data (https://en.wikipedia.org/wiki/Maximum likelihood). In other words, this specific algorithm is an iterative method for finding maximum likelihood or maximum a posteriori estimates of parameters in statistical models, where the model depends on unobserved latent variables. Missing data analyses using Monte Carlo technique show that the Expectation-Maximization Algorithm is more reliable for missing-data imputation when compared to pairwise and listwise deletion (Malhotra, 1987; Graham \& Donaldson, 1993). Hence, we found it as an appropriate method in the present study. 
All following analyses were computed with these replaced values for the outliers and the

272 original raw-scores. The dependent variables (the 5 time perspective dimensions, psychological

273 well-being and temporal satisfaction) per affective profile were normally distributed with a

274 skewness between .07 to -.77 and a kurtosis between .01 and -.84 . Because our sample size is

275 relatively large, these values are reasonable (see Tabachnick \& Fidell, 2007, p.80). Visual

276 inspection indicated no threats to linearity or homoscedasticity on the dependent variables (i.e.,

277 time perspective and well-being) for each affective profile. Thus, the assumptions were met to

278 conduct the SEM.

Multivariate outliers. The 5 time perspective dimensions, psychological well-being and

280

281

282

283

284

285 temporal satisfaction with life were checked for multivariate outliers within the affective profiles. The multivariate outlier detection by Mahalanobis distance identified three multivariate outliers, which were replaced as described above (Tabachnick \& Fidell, 2007, p.76).

Multicollinearity and singularity. The correlations between dependent variables were all below -.59 . These correlations, for each profile, were below -.54 . Therefore, multicollinearity or singularity was judged as unlikely to be present or a problem (see Tabachnick \& Fidell, 2007, p.88, who recommend .90 as threshold).

Differences in psychological well-being and temporal satisfaction with life between affective profiles were investigated using a MANOVA. Psychological well-being and temporal satisfaction with life served as dependent variables, affective profiles were the independent variables. A second MANOVA investigated differences between affective profiles in the 5 dimensions of time perspective. Here, the mean scores on each of the time perspective dimension scale served as dependent variables and affective profile as independent variable. Each MANOVA, if significant regarding Pillai's criterion, was followed up by ANOVA to test 
294 differences between individuals with distinct profiles on each of the dependent variables and 295 then we conducted post-hoc tests with Bonferroni correction to investigate which profiles 296 differed from each other.

297 Homogeneity of variance-covariance matrices. The Box's $M$ test was significant at $p<$ 298.001 for the first MANOVA (i.e., the analysis investigating differences in psychological well299 being and temporal satisfaction with life between affective profiles) and at $p<.02$ (see Huberty $300 \&$ Petoskey 2000, who suggest that a $p$ value higher than the cut-off of $p=.005$ does not violate 301 the assumption of homogeneity of variance-covariance matrices) for the second MANOVA (i.e., 302 the analysis investigating differences between affective profiles in the 5 dimensions of time perspective). Nevertheless, the groups in each profile are relatively large and there are only small 304 group size differences (with a ratio of 1.69:1 regarding profiles the largest group was 222 self305 destructive profile and the smallest was 131 low affective profile). As a preliminary check for 306 robustness, large groups have larger variances and covariances in the dependent variables, 307 compared to small groups with smaller sizes; however, in our data there were only small 308 differences in the sizes of the variances and covariances. For example, regarding variances for 309 the first MANOVA the ratio of largest (.27) to smallest (.10) variance was 2.70:1 (temporal satisfaction with life). Regarding variances for the second MANOVA the ratio of largest (.31) to 311 smallest (.22) variance was 1.41:1 (present fatalistic). MANOVA makes the assumption that the 312 within-group covariance matrices are equal. If the design is balanced so that there are an equal 313 number of observations in each cell, the robustness of the MANOVA tests is guaranteed. Thus, 314 the assumptions of homogeneity of variance and covariance matrices were met for the 315 conduction of MANOVAs (see Tabachnick \& Fidell, 2007). Moreover, we used Pillai's criterion 
316 instead of Wilks' lambda because Pillai's criterion is more robust, appropriate, and more stringent

317 criterion against heterogeneity of variance-covariance (see Tabachnick \& Fidell, 2007, p.252).

318 Residuals of the covariances among observed variables in the SEM. All the residual

319 covariances and standardized residual covariances among observed variables for each profile

320 were zero, with the exception of covariances between psychological well-being and temporal life

321 satisfaction which were between .10 for residual covariance and 3.28 for standardized residual

322 covariance for each affective profile. Nevertheless, the residuals for both variables were still

323 centered around zero and the sample size used here is relatively large, thus, our multi-group

324 moderation model fits the data reasonably well and the residuals were considered symmetrical

325 (see Tabachnick \& Fidell, 2007, p. 684).

326

327

Results

328

Differences in psychological well-being and temporal satisfaction with life between affective 329 profiles

The affective profiles had a significant effect on the psychological well-being and temporal satisfaction with life $(F(6,1432)=43.80, p<.001$, Pillai'sTrace=.31, Observed Power $=1.00)$. The groups differed in psychological well-being $(F(3,716)=59.57, p<.001$, Observed Power $=$ $1.00)$ and in temporal satisfaction with life $(F(3,716)=77.37, p<.001$, Observed Power $=1.00)$. Individuals with a self-fulfilling profile scored higher in psychological well-being and in temporal satisfaction with life than individuals with any of the other profiles. Individuals with a

high affective and low affective profile scored higher in both temporal satisfaction with life and Table. 1). 


\section{Differences in the 5 dimensions of time perspective between affective profiles}

340 The affective profiles had a significant effect on the time perspective dimensions $(F(15,2142)=$

341 18.18, $p<.001$, Pillai'sTrace $=.35$, Observed Power $=1.00$ ). The groups differed in the past

342 negative $(F(3,716)=69.84, p<.001$, Observed Power $=1.00)$, past positive $(F(3,716)=9.40$,

$343 p<.001$, Observed Power $=1.00)$, present fatalistic $(F(3,716)=22.30, p<.001$, Observed

344 Power $=1.00)$, present hedonistic $(F(3,716)=5.76, p<.001$, Observed Power $=.95)$, and future

$345(F(3,716)=16.69, p<.001$, Observed Power $=1.00)$ dimensions. Compared to individuals with

346 any of the other profiles, individuals with a self-destructive profile scored higher in past negative

347 and present fatalistic time perspective. Individuals with a self-fulfilling profile and a high

348 affective profile scored higher in past positive time perspective compared to individuals with a

349 self-destructive profile. Individuals with a self-fulfilling profile and a high affective profile

350 scored higher in present hedonistic as compared to individuals with a low affective time

351 perspective. Individuals with a self-fulfilling profile and a high affective profile scored higher in

352 the future dimension compared to individuals with a self-destructive profile and a low affective

353 profile. See Table 1 for the details in which the results from the post hoc tests, Bonferroni 354 correction: $p=.05 \div 5=.01$, are presented.

355

356

357

358

359

360

361

\section{Table 1 should be here}

\section{Multi-group moderation analysis}

To investigate which of the time perspective dimensions were related to both psychological wellbeing and temporal satisfaction with life we performed a path analysis, using AMOS (version 20) - in order to estimate interaction/moderation effects between affective profiles as the moderator, time perspective dimensions as independent variables, and psychological well-being and temporal satisfaction with life as the outcome (see Figure 1). The structural equation model 
362 of multi-group analysis showed a Chi-square $=23.22 ; D F=4 ; p<.001$. The large sample in our

363 present study $(N=720)$ may influence the Chi-square value to be significant (see Tabachnick \&

364 Fidell, 2007, p. 695). However, the path model yielded a good fit, as indicated by comparative fit

365 index $=.98 ;$ goodness of fit index $=.99 ;$ incremental fit index $=.98$, normed fit index $=.97$ and

366 root mean square error of approximation $=.08$.

367 Four multi-group moderation analyses, one for each profile, showed that $16 \%$ to $33 \%$ of 368 the variance of psychological well-being and $29 \%$ to $40 \%$ of the variance of temporal 369 satisfaction with life could be explained by the 5 time perspective dimensions (see Table 2). 370 Specifically, psychological well-being was significantly predicted by past positive and present

371 hedonistic across all affective profiles (see Figure 2 to 5). This suggests that the type of affective 372 profile does not moderate the influence of these two time perspective dimensions on 373 psychological well-being. For individuals with a self-destructive profile, psychological well374 being was significantly predicted by past negative, present fatalistic, and future (see Figure 2). 375 Among individuals who experience high levels of positive affect (i.e., high affective and self376 fulfilling), psychological well-being was significantly predicted by the present fatalistic 377 dimension (see Figure 4 and 5). Temporal satisfaction with life was significantly predicted by 378 past negative and past positive across all affective profiles (see Figure 2 to 5 ). This suggests that 379 the type of affective profile does not moderate the influence of these two time perspective 380 dimensions on temporal satisfaction with life. Nevertheless, for individuals with a self381 destructive profile, temporal satisfaction with life was predicted by the future time perspective 382 dimension (see Figure 2).

\section{Discussion}


385 This study revealed differences in time perspective and well-being depending on an individual's

386 affective profile (for a summary of the results see Figure 6). By looking at the differences

387 between individuals at the diametrical ends of the model we first found that individuals with a

388 self-fulfilling profile (i.e., high positive and low negative affect), compared to individuals with a

389 self-destructive profile (i.e., low positive and high negative affect), scored high on psychological

390 well-being, high on temporal life satisfaction, high on the past positive and future time

391 perspective dimensions, and low in both the past negative and present fatalistic time perspective

392 dimensions (see Figure 6, horizontal black arrows). This fits the description of a "balanced" time

393 perspective that promotes high levels of well-being (Boniwell et al. 2010). Also being

394 diametrically different to individuals with a low affective profile (low positive and low negative

395 affect), individuals with a high affective profile (high positive and high negative affect) scored

396 higher on the past negative, the present hedonistic and the future time perspective dimensions

397 (see Figure 6, vertical black arrows). As in earlier studies (e.g., Garcia \& Siddiqui, 2009a), no

398 differences in well-being were found between individuals with high and low affective profiles.

399 Nevertheless, individuals with any of these two profiles scored higher on both psychological

400 well-being and temporal life satisfaction when compared to those with a self-destructive profile.

401 Hence, a low level of positive affect together with a high level of negative affect appears to be

402 detrimental for psychological well-being and life satisfaction.

403 One of the strengths of the affective profiles model is that it allows the comparison of

404 people who differ in one affectivity dimension while keeping the other constant. In this way we

405 get to observe associations within this complex adaptive system (cf. Cloninger \& Garcia, 2015).

406 For example, decreases in a negative view of the past (i.e., the past negative time perspective

407 dimension) might lead to high positive affect when negative affect is high (see grey arrows in 
408 Figure 6: self-destructive vs. high affective) but to low negative affect when positive affect is

409 either high (see grey arrows in Figure 6: high affective vs. self-fulfilling) or low (see grey arrows

410 in Figure 6: self-destructive vs. low affective). Increases in the future perspective dimension

411 seem to only be associated with increases in positive affect; both when negative affect is high

412 (see grey arrows in Figure 6: self-destructive vs. high affective) and when negative affect is low

413 (see grey arrows in Figure 6: low affective vs. self-fulfilling). In contrast, increases in the present

414 hedonistic dimension seem to lead to higher levels of positive affect only when negative affect is

415 low (see grey arrows in Figure 6: low affective vs. self-fulfilling). Low levels in negative affect

416 in turn were associated to decreases in the past negative time perspective dimension. In other

417 words, to live happy in the present we need to let go of our past. The act of letting go of struggles

418 is indeed one of the first steps of self-aware knowledge that is part of the Science of Well-Being

419 (see Cloninger, 2004). All these complex interactions give a picture of how time perspective 420 dimensions are associated to the affectivity system. Next we discuss how these dimensions 421 predict well-being depending on the person's own affective profile.

422

423

424

425

426

427

428

429

430

\section{Figure 6 should be about here}

Interestingly, certain time perspective dimensions influenced well-being depending on the person's type of affective profile. Indeed, moderation analysis showed that the past positive and the present hedonistic time perspectives were positively associated to psychological well-being among individuals with any type of affective profile, while the present fatalistic dimension was negatively associated to psychological well-being in three out of the four affective profile groups - the exception was for individuals with a low affective profile. Individuals with a low affective profile have been found to downplay their emotions by either neutralizing positive and negative stimuli or, when faced with many positive things in life, to value neutral stimuli as more 
431 negative (Garcia \& Siddiqui, 2009ab; Garcia, Rosenberg, Erlandsson \& Siddiqui, 2010).

432 Individuals with a low affective profile probably use these strategies in order to stay in an

433 affective state that is more in tune to their profile. Together with our findings here (i.e., the

434 negative effect of the present fatalistic time perspective on well-being among people with any

435 profile but among individuals with a low affective profile), this earlier findings might suggest

436 that individuals with a low affective profile achieve homeostasis through being fatalistic of their

437 present, that is, seeing their life path as controlled by external forces, avoiding to worry about the

438 future because they also see it as uncontrollable, believing in luck or fate rather than hard work,

439 and avoid setting goals. This strategy does indeed help individuals with a low affective profile to

440 prevent unhappiness (i.e., low levels of negative affect) and is certainly in line with how their

441 affectivity system dynamically regulates itself (cf. self-regulatory theory; Higgins, 2001). In

442 other words, by being fatalistic about their present they prevent becoming disappointed and just

443 the absence of that possible disappointment makes them feel satisfied with their life (Garcia,

444 Rosenberg, Erlandsson \& Siddiqui, 2010; see also Fredriksson, 2006; Garcia \& Siddiqui, 2009a;

445 Ramsay et al., 2015). Of course, at the same time the usage of this strategy limits their

446 experience of positive emotions, which might explain why they are not as satisfied with life as

447 individuals with a self-fulfilling profile. The pattern that emerges for temporal life satisfaction

448 differs from the one for psychological well-being. Temporal life satisfaction was associated

449 positively with past positive and negatively with past negative for all four profiles. Suggesting

450 that these specific time perspective dimensions are equally important for life satisfaction,

451 independently of the individual's type of affective profile. In other words, the associations

452 between nostalgic and positive attitudes towards the past and/or a general negative view of the

453 past are both associated to life satisfaction regardless of how the individual's affectivity system 
454 is structured (i.e., high/low positive/negative affect). Indeed, others have suggested that the

455 ability to let go of past struggles is related to feelings of hope that one can manage the present 456 and the future (i.e., self-directedness; Cloninger, 2004). Feelings of hope, although positive, are

457 not embedded in our affectivity system; they are rather associated to frontal lobe activity 458 (Cloninger, 2004). In addition, for individuals with a self-destructive profile the future time 459 perspective dimension was also associated to high levels of life satisfaction. Thus, suggesting a 460 unique association among individuals with a self-destructive profile' life satisfaction and their 461 ability to plan and achieve future goals and their tendency to postpone direct gratification in 462 favor of long-term goals.

\section{Limitations}

464 Time perspective manipulation has been reported to influence experienced affect (Murgraff et al. 465 1999; Strack et al. 1985) and vice versa. The present analysis of time perspective, however, 466 presents an affective profile background derived from healthy volunteers. Those individuals 467 presenting less healthy profiles, such as the self-destructive profiles, may arise from a 468 "prodromal" phase of affective ill-being or a "past-experienced" affective condition. Without 469 repeated measures or a sub-longitudinal analysis, the status of differential time perspectives over 470 the affective profiles remains uncertain. Moreover, one important limitation is the fact that the 471 sample was constituted of students and pupils.

\section{Concluding remarks}

473 The interactions found here go beyond the postulation suggesting that the only way of promoting 474 well-being, at least with regard to time dimensions, is a "balanced" time perspective. Instead, we

475 present a more person-centered approach to achieve higher levels of emotional, cognitive, and 476 psychological well-being. We suggest that future research might consider personality profiles to 
477 address the question of how interventions might affect a person's outlook on life (cf. Garcia \&

478 Rosenberg, 2016; Cloninger \& Zohar, 2011).

479

480

481

482

483

484

485

486

487

488

489

490

491

492

493

494

495

496

497

498

\section{References}

Archer, T., Adolfsson, B., Karlsson, E. (2008). Affective personality as cognitive-emotional presymptom profiles regulatory for self-reported health predispositions. Neurotoxicity Research, 14, 21-44.

Boniwell, I., Osin, E., Linley, P. A., \& Ivanchenko, G. (2010). A question of balance: Time perspective and well-being in British and Russian samples. Journal of Positive Psychology, 5 (1), 24-40.

Bruehlman-Senecal E, Ayduk O (2015) This too shall pass: temporal distance and the regulation of emotional distress. J Pers Soc Psychol. 108(2):356-75. doi: 10.1037/a0038324.

Clarke, P. J., Marshall, V. M., Ryff, C. D., \& Wheaton, B. (2001). Measuring psychological well-being in the Canadian study of health and aging. International Psychogeriatrics, $13,79-90$.

Cloninger, C. R. (2004). Feeling good: The Science of Well-being. New York: Oxford University Press.

Cloninger, C. R., \& Garcia, D. (2015). The Heritability and Development of Positive Affect and Emotionality. In M. Pluess (Ed.), Genetics of Psychological Well-Being - The Role of Heritability and Genetics in Positive Psychology (97-113). New York: Oxford University Press.

Cloninger, C. R., \& Zohar, A. H. (2011). Personality and the Perception of Health and Happiness. Journal of Affective Disorders, 128(1), 24-32. doi:10.1016/j.jad.2010.06.012 
499 Demeyer I, De Raedt R (2013) Attentional bias for emotional information in older adults: the 500 role of emotion and future time perspective. PLoS One. 8(6):e65429. doi: $501 \quad$ 10.1371/journal.pone.0065429.

502 Díaz-Morales, J. F. (2006). Estructura factorial y fiabilidad del Inventario de Perspective 503 Temporal de Zimbardo. Psicothema, 18, 565-567.

504 Fredrickson, B.L. (2006). The broaden-and-build theory of positive emotions. In M. 505 Csikszentmihalyi, \& I.S. Csikszentmihalyi (Eds.), A life worth living: Contributions to 506 positive psychology (pp. 85-103). New York: Oxford University Press.

507 Garcia, D (2011). Two Models of Personality and Well-Being among Adolescents. Personality 508 and Individual Differences, 50, 1208-1212. DOI: 10.1016/j.paid.2011.02.009.

509 Garcia, D. (2013). La vie en Rose: High Levels of Well-Being and Events Inside and Outside 510 Autobiographical Memory. Journal ofHappiness Studies. DOI: 10.1007/s10902-0139443-X.

512 Garcia, D., Adrianson, L., \& Archer, T., Rosenberg, P. (2015). The Dark Side of The Affective 513 Profiles: Differences and Similarities in Psychopathy, Machiavellianism, and Narcissism. Sage Open, 5 (4). DOI: 10.1177/2158244015615167.

515 Garcia D, MacDonald S, Archer T (2015) Two different approaches to the affective profiles 516 model: median splits (variable-oriented) and cluster analysis (person-oriented). PeerJ. 517 3:e1380. doi: 10.7717/peerj.1380.

518 Garcia, D., Nima, A. A., \& Kjell, O. N. E. (2014). The affective profiles, psychological well519 being, and harmony: environmental mastery and self-acceptance predict the sense of a 520 harmonious life. PeerJ2:e259. DOI: 10.7717/peerj.259. 
521 Garcia, D., \& Rosenberg, P. (2016). The Dark Cube: Dark and Light Character Profiles. PeerJ $522 \quad$ 4:e1675; DOI: $10.7717 /$ peerj.1675.

523 Garcia, D., Rosenberg, P., Erlandsson, A., \& Siddiqui, A. (2010). On Lions and Adolescents:

524 Affective Temperaments and the Influence of Negative Stimuli on Memory. Journal of 525 Happiness Studies, 11, 477-495. DOI: 10.1007/s10902-009-9153-6.

526 Garcia, D., Rosenberg, P., \& Siddiqui, A. (2011). Tomorrow I Could Be in Trouble...But The 527 Sun Will Come OutNextYear: The Effectof Temporal Distance on Adolescents' Judgmentsof Life Satisfaction. Journal of Adolescence, 34, 751-757. DOI:

Garcia, D., \& Siddiqui, A. (2009a). Adolescents' Affective Temperaments: Life Satisfaction, Interpretation and Memory of events. The Journal of Positive Psychology, 4, 155-167. DOI: $10.1080 / 17439760802399349$.

Garcia, D, \& Siddiqui, A. (2009b). Adolescents' Psychological Well-Being and Memory for Life 534 Events: Influences on Life Satisfaction with Respect to Temperamental Dispositions. Journal of Happiness Studies, 10,387 - 503. DOI: 10.1007/s10902-008-9096-3.

536 Graham, J. W., \& Donaldson, S. I. (1993). Evaluating interventions with differential attrition: The importance of nonresponse mechanisms and use of follow-up data. Journal of Applied Psychology, 78(1), 119-128.

Higgins, E. T. (2001). Promotion and prevention experiences: Relating emotions to nonemotional motivational states. In J. P. Forgas (Ed.), Handbook of affect and social cognition (pp. 186-211). Hillsdale, NJ: Lawrence Erlbaum Associates. 
542 Huberty, C. J., \& Petoskey, M. D. (2000). Multivariate analysis of variance and covariance. In

543

544

545

546

547

548

549

550

551

552

553

554

555

556

557

558

559

560

561

562

563

H. Tinsley and S. Brown (Eds.) Handbook of applied multivariate statistics and mathematical modeling. New York: Academic Press.

Liniauskaite, A., \&Kairys, A. (2009). The Lithuanian version of the Zimbardo Time Perspective Inventory (ZTPI). Psichologija, 40, 66-87.

Malhotra, N. K. (1987). Analyzing marketing research data with incomplete information on the dependent variable. Journal of Marketing Research, 24, 74-84.

Milfont, T. L., Andrade, P. R., Belo, R. P., Pessoa, V. S. (2008). Testing Zimbardo Time Perspective Inventory in a Brazilian sample. Interamerican Journal of Psychology, 42, 49-58.

Murgraff V1, McDermott MR, White D, Phillips K (1999). Regret is what you get: the effects of manipulating anticipated affect and time perspective on risky single-occasion drinking. Alcohol 34(4):590-600.

Nima, A. A., Archer, T., \& Garcia, D. (2012). Adolescents' happiness-increasingStrategies, Temperament, and Character: Mediationmodels on SubjectiveWell-Being. Health, 4, 802-810. DOI: 10.4236/health.2012.410124.

Nima, A. A., Archer, T., \& Garcia, D. (2013).The Happiness-Increasing Strategies Scales in a Sample of Swedish Adolescents.International Journal of Happiness and Development, $1,196-211$.

Nima, A. A., Rosenberg, P., Archer, T., \& Garcia, D. (2013). Anxiety, Affect, Self-esteem, and Stress: Mediation and Moderation Effects on Depression. PLOS ONE. DOI: 10.1371/journal.pone.0073265. 
564 Norlander, T., Bood, S.-Å., \& Archer, T. (2002). Performance during stress: Affective 565 personality age, and regularity of physicalexercise. Social Behavior and Personality, 30,

566 495-508.

567 Pavot, W., Diener, E., \&Suh, E. (1998). The temporal satisfaction with life 568 scale.JournalofPersonality Assessment, 2, 340-354.

569

570

571

572

573

574

575

576

577

578

579

580

581

582

583

584

585

586

Ramsey JL, Neupert SD, Mroczek DK, Spiro A (2015) The Effects of Daily Co-Occurrence of Affect on Older Adults' Reactivity to Health Stressors. Psychol Health. 2015 Oct 30:131.

Sailer, U., Rosenberg, P., Nima, A. A., Gamble, A., Gärling, T., Archer, T., Garcia, D. (2014). A Happier and Less Sinister Past, a More Hedonistic and Less Fatalistic Present and a more Structured Future: Time Perspective and Well-Being. PeerJ2:e303. DOI: 10.7717/peerj.303.

Schütz, E., Archer, T. \& Garcia, D. (2013). Character Profiles and Adolescents' Self-reported Affect. Personality and Individual Differences, 54, 841-844. DOI: 10.1016/j.paid.2012.12.020.

Shmotkin D, Eyal N (2003). Psychological Time in Later Life: Implications for Counseling. Journal of Counseling and Development 81(3):259-67.

Strack F, Schwarz N, Gschneidinger E (1985). Happiness and reminiscing: The role of time perspective, affect, and mode of thinking. Journal of Personality and Social Psychology, Vol 49(6): 1460-1469.

Tabachnick, B. G. \& Fidell, L. S. (2007). Using multivariate statistics (5th, international ed). Boston: Pearson Education.

Wallace M, Rabin AI.Temporal experience. Psychol Bull. 1960 May;57:213-36. 
587 Watson, D., \& Clark, L. A. (1994). The PANAS-X: Manual for the positive and negative affect 588 schedule — expanded form. Boise: University of Iowa Press.

589 Watson, D., Clark, L. A., \& Tellegen, A. (1988). Development and validation of brief measures $590 \quad$ of positive and negative affect: The PANAS scale. Journal of Personality and Social 591 Psychology, 54, 1063-1070.

592 Wuensch, K. (2005). Using SPSS to screen data. Retrieved August 28, 2011, from $593 \quad$ http://core.ecu.edu/psyc/wuenschk/SPSS/Screen-SPSS.doc

594 Zimbardo, P.G., \& Boyd, J.N. (1999). Putting time in perspective: A valid, reliable individual595 differences metric. Journal of Personality and Social psychology, 77, 1271-1288. 
596 Table 1. Mean scores and standard deviation $(s d)$ in psychological well-being, temporal life 597 satisfaction and the time perspective dimensions for each affective profile.

598 Notes.Values represent mean scores $\pm s d ;{ }^{*} p<.05 ; * * p<.01{ }^{* * *} p<.001 ;{ }^{\mathrm{D}}$ higher compared to 599 the self-destructive; ${ }^{\mathrm{L}}$ higher compared to the low affective; ${ }^{\mathrm{H}}$ higher compared to the high 600 affective; F higher compared to the self fulfilling.

601

602 Table 2. Structural coefficients for the multi-group moderation analyses using the type of 603 affective profile as the moderator, the time perspective dimensions as predictors and both 604 psychological well-being and temporal satisfaction with life as the outcomes.

605 Note: Significant regression weights are shown in bold type.

606

607 Figure 1. Hypothesized structural equation model using the time perspective dimensions as 608 predictors of both psychological well-being and temporal satisfaction with life.

609

610 Figure 2. SEM for the self-destructive profile showing all correlations (between time perspective 611 dimensions) and all paths (from time perspective to well-being) and their standardized parameter 612 estimates.

613 Note: Chi-square $=23.22 ; d f=4 ; p<.001 ;$ comparative fit index=.98; goodness of fit index $=$ $614.99 ;$ incremental fit index $=.98$, normed fit index $=.97$ and root mean square error of approximation $615=.08$. Red standardized parameter estimates of regression weights are significant at the $p<.001$ 616 level, blue standardized parameter estimates of regression weights are significant at the $p<.01$ 617 level and green standardized parameter estimates of regression weights are significant at the $p<$ $618.05(n=222)$. 
619

620 Figure 3. SEM for the low affective profile showing all correlations (between time perspective 621 dimensions) and all paths (from time perspective to well-being) and their standardized parameter 622 estimates.

623 Note: Chi-square $=23.22 ; d f=4 ; p<.001 ;$ comparative fit index $=.98$; goodness of fit index $=$ $624.99 ;$ incremental fit index $=.98$, normed fit index $=.97$ and root mean square error of 625 approximation $=.08$. Red standardized parameter estimates of regression weights are significant 626 at the $p<.001$ level, blue standardized parameter estimates of regression weights are significant 627 at the $p<.01$ level and green standardized parameter estimates of regression weights are 628 significant at the $p<.05(n=131)$.

629

630 Figure 4. SEM for the high affective profile showing all correlations (between time perspective 631 dimensions) and all paths (from time perspective to well-being) and their standardized parameter 632 estimates.

633 Note: Chi-square $=23.22 ; d f=4 ; p<.001 ;$ comparative fit index $=.98$; goodness of fit index $=$ $634.99 ;$ incremental fit index $=.98$, normed fit index $=.97$ and root mean square error of 635 approximation $=.08$. Red standardized parameter estimates of regression weights are significant 636 at the $p<.001$ level, blue standardized parameter estimates of regression weights are significant 637 at the $p<.01$ level and green standardized parameter estimates of regression weights are 638 significant at the $p<.05(n=150)$.

639 
640 Figure 5. SEM for the self-fulfilling profile showing all correlations (between time perspective 641 dimensions) and all paths (from time perspective to well-being) and their standardized parameter 642 estimates.

643 Note: Chi-square $=23.22 ; d f=4 ; p<.001 ;$ comparative fit index $=.98 ;$ goodness of fit index $=$ $644.99 ;$ incremental fit index $=.98$, normed fit index $=.97$ and root mean square error of 645 approximation $=.08$. Red standardized parameter estimates of regression weights are significant 646 at the $p<.001$ level, blue standardized parameter estimates of regression weights are significant 647 at the $p<.01$ level and green standardized parameter estimates of regression weights are 648 significant at the $p<.05(n=217)$.

649

650 Figure 6. Differences (black arrows) found between individuals with affective profiles that are at 651 their extremes of the model: self-destructive versus self-fulfilling (low-high positive affect, high652 low negative affect) and low affective versus high affective (low-high positive affect, low-high 653 negative affect). Differences (grey arrows) found when individuals were matched in one 654 affective dimension, and differed in the other (i.e., within differences): self-destructive versus 655 high affective (matching: high-high negative affect, differing: low-high positive affect), self656 destructive versus low affective (matching: low-low positive affect, differing: high-low negative 657 affect), high affective versus self-fulfilling (matching: high-high positive affect, differing: high658 low negative affect), and low affective versus self-fulfilling (matching: low-low negative affect, 659 differing: low- high positive affect).

660 Note. Reprinted with permission from Well-Being and Human Performance Sweden AB. 


\section{Table $\mathbf{1}$ (on next page)}

Table 1

Mean scores and standard deviation ( $s d$ ) in psychological well-being, temporal life satisfaction and the time perspective dimensions for each affective profile. Notes. Values represent mean scores $\pm s d ; * p<.05 ;{ }^{* *} p<.01 .{ }^{* *} p<.001 ;{ }^{D}$ higher compared to the selfdestructive; ' higher compared to the low affective; ${ }^{H}$ higher compared to the high affective; ${ }^{\mathrm{F}}$ higher compared to the self fulfilling. 
1 Table 1. Mean scores and standard deviation $(s d)$ in psychological well-being, temporal life satisfaction and the time perspective 2 dimensions for each affective profile.

\begin{tabular}{|c|c|c|c|c|}
\hline & $\begin{array}{l}\text { Self-destructive } \\
\qquad n=222\end{array}$ & $\begin{array}{l}\text { Low-affective } \\
\qquad n=131\end{array}$ & $\begin{array}{l}\text { High-affective } \\
\qquad n=150\end{array}$ & $\begin{array}{l}\text { Self-fulfilling } \\
\qquad n=217\end{array}$ \\
\hline Psychological Well-Being & $3.86 \pm .49$ & $4.18 \pm .58^{\mathrm{D}^{* * *}}$ & $4.31 \pm .54^{\mathrm{D}^{* * *}}$ & $4.57 \pm .63^{\mathrm{D}, \mathrm{L}, \mathrm{H}^{* * *}}$ \\
\hline Temporal Life Satisfaction & $3.42 \pm 1.11$ & $4.36 \pm 1.03^{\mathrm{D}^{* * *}}$ & $4.38 \pm 1.07^{\mathrm{D}^{* * *}}$ & $4.89 \pm .89^{\mathrm{D}, \mathrm{L}, \mathrm{H}^{* * *}}$ \\
\hline Past Negative & $3.29 \pm .66^{\mathrm{L}, \mathrm{H}, \mathrm{F}^{* * *}}$ & $2.57 \pm .62$ & $2.94 \pm .69^{\mathrm{L}, \mathrm{F}^{* * *}}$ & $2.44 \pm .64$ \\
\hline Past Positive & $3.20 \pm .64$ & $3.34 \pm .60$ & $3.45 \pm .63^{\mathrm{D}^{* *}}$ & $3.49 \pm .63^{\mathrm{D}^{* * *}}$ \\
\hline Present Fatalistic & $2.58 \pm .52^{\mathrm{L}, \mathrm{F}^{* * *}, \mathrm{H}^{* *}}$ & $2.32 \pm .47$ & $2.38 \pm .56^{\mathrm{F}^{* *}}$ & $2.19 \pm .46$ \\
\hline Present Hedonistic & $3.09 \pm .45$ & $3.00 \pm .46$ & $3.22 \pm .45^{\mathrm{L}^{* *}}$ & $3.17 \pm .53^{L^{*}}$ \\
\hline Future & $3.14 \pm .48$ & $3.14 \pm .45$ & $3.39 \pm .45^{\mathrm{D}, \mathrm{L}^{* * *}}$ & $3.38 \pm .47^{\mathrm{D}, \mathrm{L}^{* * *}}$ \\
\hline
\end{tabular}

3 Notes. ${ }^{*} p<.05 ;{ }^{*} p<.01 ; * * * p<.001 ;{ }^{\mathrm{D}}$ higher compared to the self-destructive; ${ }^{\mathrm{L}}$ higher compared to the low affective; ${ }^{\mathrm{H}}$ higher 4 compared to the high affective; ${ }^{\mathrm{F}}$ higher compared to the self fulfilling. 


\section{Table 2 (on next page)}

Table 2

Structural coefficients for the multi-group moderation analyses using the type of affective profile as the moderator, the time perspective dimensions as predictors and both psychological well-being and temporal satisfaction with life as the outcomes. Note: Significant regression weights are shown in bold type. 
1 Table 2. Structural coefficients for the multi-group moderation analyses using the type of

2 affective profile as the moderator, the time perspective dimensions as predictors and both

3 psychological well-being and temporal satisfaction with life as the outcomes.

\begin{tabular}{|c|c|c|c|c|c|}
\hline Predictor & Outcome & $\beta$ & SE & $B$ & $P$ \\
\hline \multicolumn{6}{|c|}{ Self-destructive $=222$} \\
\hline Past negative & & -.18 & .05 & -.24 & $<.001$ \\
\hline Past positive & \multirow{4}{*}{ Psychological well-being } & .27 & .05 & .35 & $<.001$ \\
\hline Present fatalistic & & -.14 & .06 & -.15 & $<.05$ \\
\hline Present hedonistic & & .15 & .07 & .13 & $<.05$ \\
\hline Future & & .16 & .06 & .15 & $<.01$ \\
\hline$R^{2}$ & .28 & & & & \\
\hline Past negative & \multirow{5}{*}{ Temporal satisfaction } & -.82 & .10 & -.49 & $<.001$ \\
\hline Past positive & & .53 & .10 & .31 & $<.001$ \\
\hline Present fatalistic & & .06 & .13 & .03 & .63 \\
\hline Present hedonistic & & .10 & .14 & .04 & .49 \\
\hline Future & & .28 & .12 & .12 & $<.05$ \\
\hline $\boldsymbol{R}^{2}$ & .40 & & & & \\
\hline \multicolumn{6}{|c|}{ Low-affective $n=131$} \\
\hline Past negative & \multirow{5}{*}{ Psychological well-being } & -.06 & .08 & -.06 & .45 \\
\hline Past positive & & .42 & .08 & .44 & $<.001$ \\
\hline Present fatalistic & & -.03 & .10 & -.03 & .75 \\
\hline Present hedonistic & & .29 & .10 & .23 & $<.01$ \\
\hline Future & & -.09 & .10 & -.07 & .35 \\
\hline $\boldsymbol{R}^{2}$ & .28 & & & & \\
\hline Past negative & \multirow{5}{*}{ Temporal satisfaction } & -.69 & .14 & -.41 & $<.001$ \\
\hline Past positive & & .61 & .14 & .35 & $<.001$ \\
\hline Present fatalistic & & .12 & .18 & .05 & .52 \\
\hline Present hedonistic & & .10 & .18 & .04 & .57 \\
\hline Future & & -.21 & .18 & -.09 & .23 \\
\hline$R^{2}$ & .30 & & & & \\
\hline \multicolumn{6}{|c|}{ High-affective $n=150$} \\
\hline Past negative & \multirow{5}{*}{ Psychological well-being } & -.02 & .06 & -.03 & .74 \\
\hline Past positive & & .35 & .06 & .41 & $<.001$ \\
\hline Present fatalistic & & -.30 & .07 & -.32 & $<.001$ \\
\hline Present hedonistic & & .37 & .09 & .31 & $<.001$ \\
\hline Future & & .13 & .08 & .11 & .10 \\
\hline
\end{tabular}




\begin{tabular}{|c|c|c|c|c|c|}
\hline$R^{2}$ & .33 & & & & \\
\hline Past negative & \multirow{5}{*}{ Temporal satisfaction } & -.64 & .13 & -.41 & $<.001$ \\
\hline Past positive & & .39 & .13 & .23 & $<.01$ \\
\hline Present fatalistic & & .04 & .15 & .02 & .78 \\
\hline Present hedonistic & & .19 & .19 & .08 & .33 \\
\hline Future & & .30 & .17 & .13 & .07 \\
\hline$R^{2}$ & .29 & & & & \\
\hline & \multirow{6}{*}{ Psychological well-being } & $=217$ & & & \\
\hline Past negative & & -.02 & .07 & -.02 & .47 \\
\hline Past positive & & .30 & .07 & .30 & $<.001$ \\
\hline Present fatalistic & & -.20 & .10 & -.14 & $<.05$ \\
\hline Present hedonistic & & .22 & .08 & .19 & $<.01$ \\
\hline Future & & .11 & .09 & .09 & .19 \\
\hline $\boldsymbol{R}^{2}$ & .16 & & & & \\
\hline Past negative & \multirow{5}{*}{ Temporal satisfaction } & -.68 & .08 & -.48 & $<.001$ \\
\hline Past positive & & .39 & .08 & .28 & $<.001$ \\
\hline Present fatalistic & & .08 & .12 & .04 & .49 \\
\hline Present hedonistic & & .12 & .10 & .07 & .25 \\
\hline Future & & .09 & .10 & .05 & .42 \\
\hline$R^{2}$ & .36 & & & & \\
\hline
\end{tabular}

4 Note: Significant regression weights are shown in bold type. 
1

Figure 1

Hypothesized structural equation model using the time perspective dimensions as predictors of both psychological well-being and temporal satisfaction with life. 


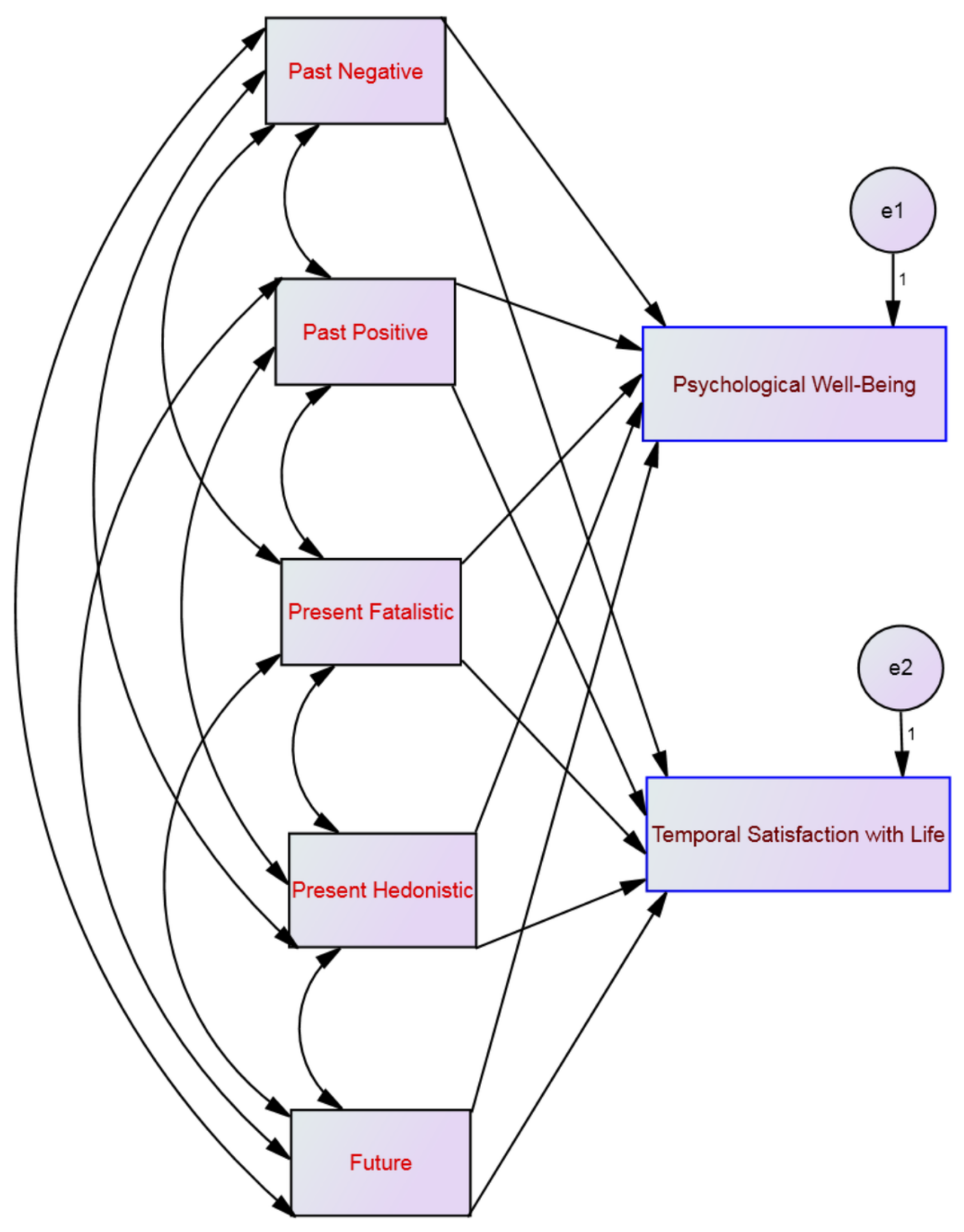




\section{2}

Figure 2

SEM for the self-destructive profile showing all correlations (between time perspective dimensions) and all paths (from time perspective to well-being) and their standardized parameter estimates. Note: Chi-square $=23.22 ; d f=4 ; p<.001 ;$ comparative fit index $=.98 ;$ goodness of fit index $=.99$; incremental fit inde $x=.98$, normed fit inde $x=.97$ and root mean square error of approximation $=.08$. Red standardized parameter estimates of regression weights are significant at the $p<.001$ level, blue standardized parameter estimates of regression weights are significant at the $p<.01$ level and green standardized parameter estimates of regression weights are significant at the $p<.05(n=222)$. 


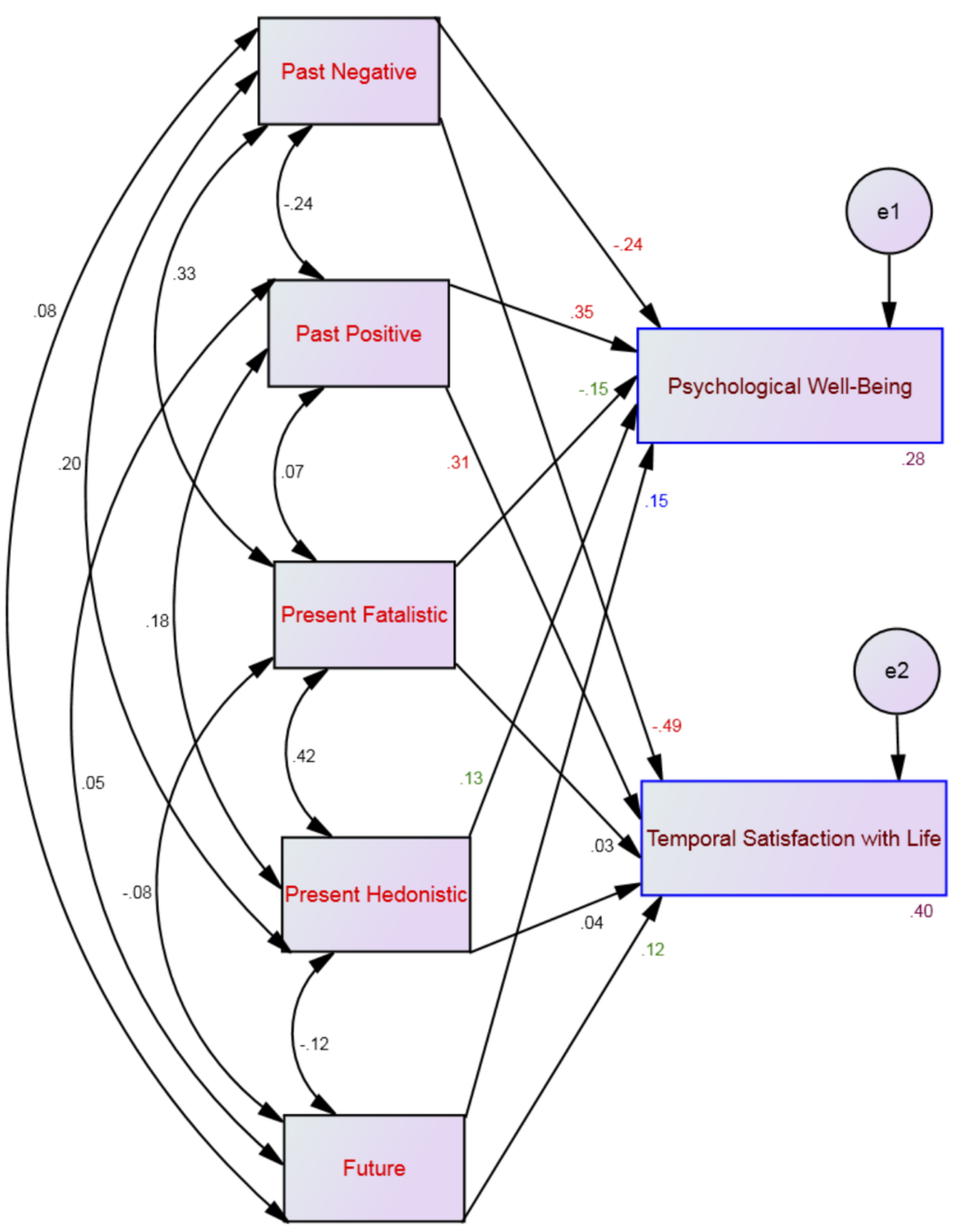




\section{3}

Figure 3

SEM for the low affective profile showing all correlations (between time perspective dimensions) and all paths (from time perspective to well-being) and their standardized parameter estimates. Note: Chi-square $=23.22 ; d f=4 ; p<.001$; comparative fit index $=$ .98; goodness of fit index $=.99$; incremental fit index $=.98$, normed fit index $=.97$ and root mean square error of approximation $=.08$. Red standardized parameter estimates of regression weights are significant at the $p<.001$ level, blue standardized parameter estimates of regression weights are significant at the $p<.01$ level and green standardized parameter estimates of regression weights are significant at the $p<.05(n=131)$. 


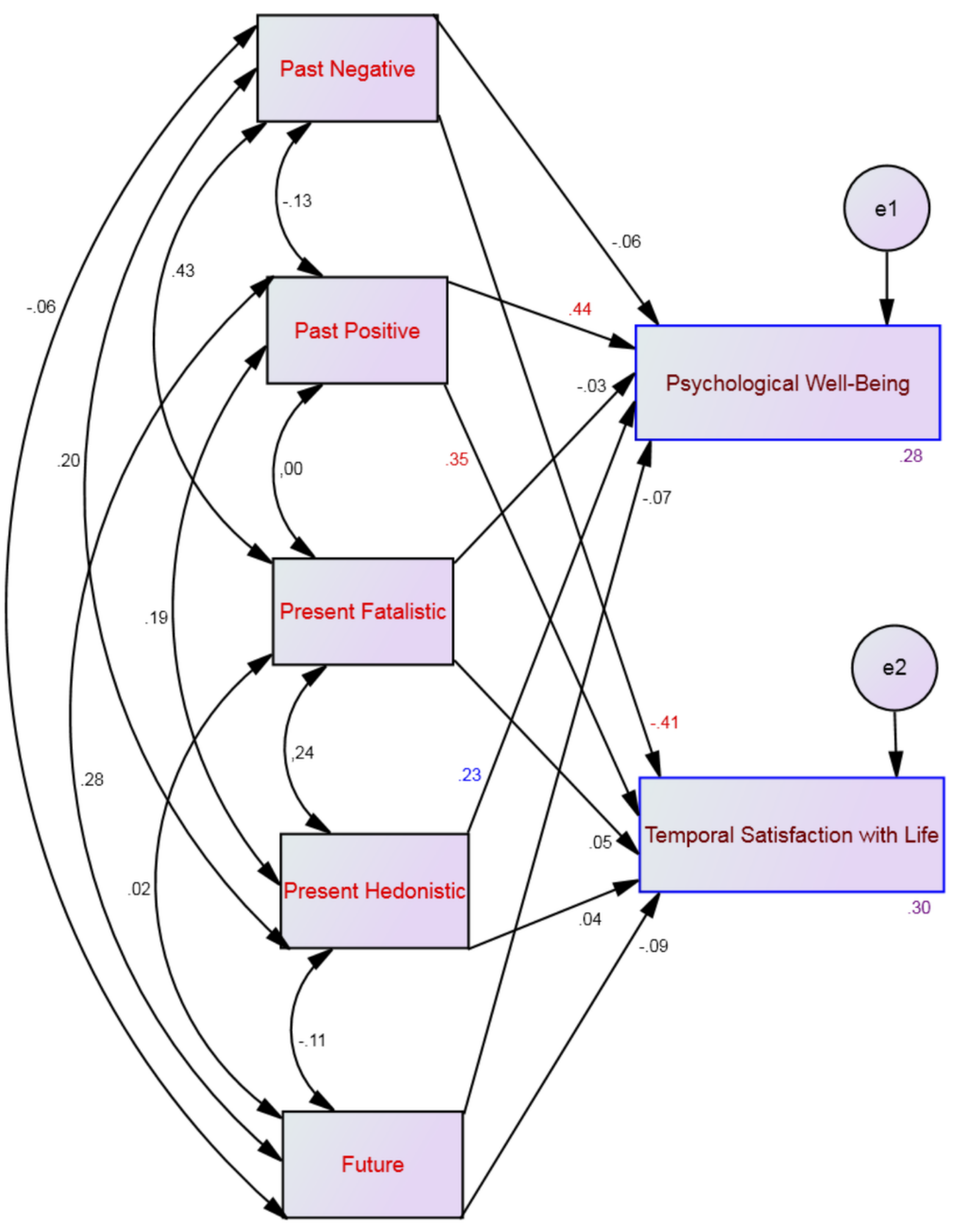




\section{4}

Figure 4

SEM for the high affective profile showing all correlations (between time perspective dimensions) and all paths (from time perspective to well-being) and their standardized parameter estimates. Note: Chi-square $=23.22 ; d f=4 ; p<.001 ;$ comparative fit index $=$ .98; goodness of fit index $=.99$; incremental fit index $=.98$, normed fit index $=.97$ and root mean square error of approximation $=.08$. Red standardized parameter estimates of regression weights are significant at the $p<.001$ level, blue standardized parameter estimates of regression weights are significant at the $p<.01$ level and green standardized parameter estimates of regression weights are significant at the $p<.05(n=150)$. 


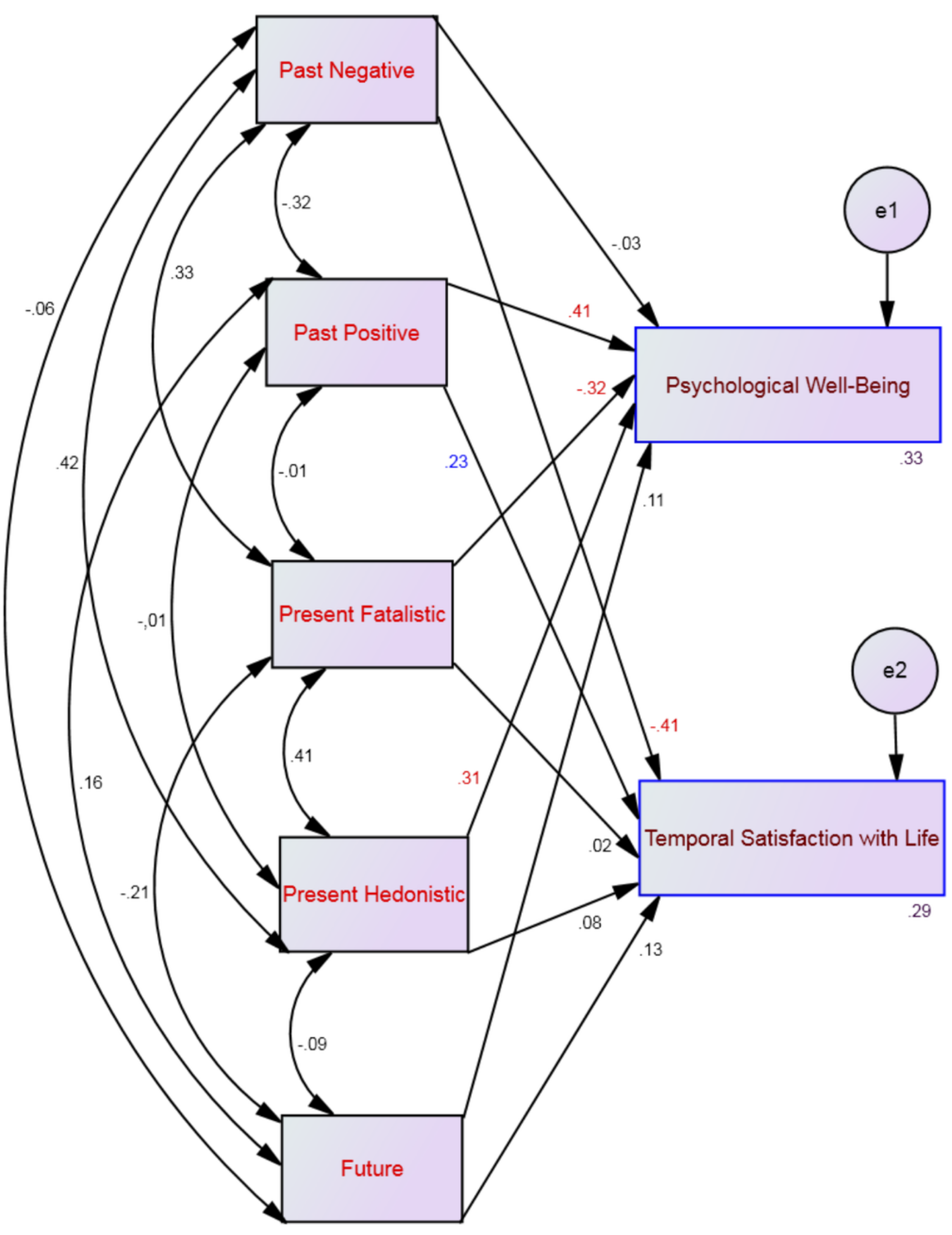




\section{5}

Figure 5

SEM for the self-fulfilling profile showing all correlations (between time perspective dimensions) and all paths (from time perspective to well-being) and their standardized parameter estimates. Note: Chi-square $=23.22 ; d f=4 ; p<.001 ;$ comparative fit index $=$ .98; goodness of fit index $=.99$; incremental fit index $=.98$, normed fit index $=.97$ and root mean square error of approximation $=.08$. Red standardized parameter estimates of regression weights are significant at the $p<.001$ level, blue standardized parameter estimates of regression weights are significant at the $p<.01$ level and green standardized parameter estimates of regression weights are significant at the $p<.05(n=217)$. 


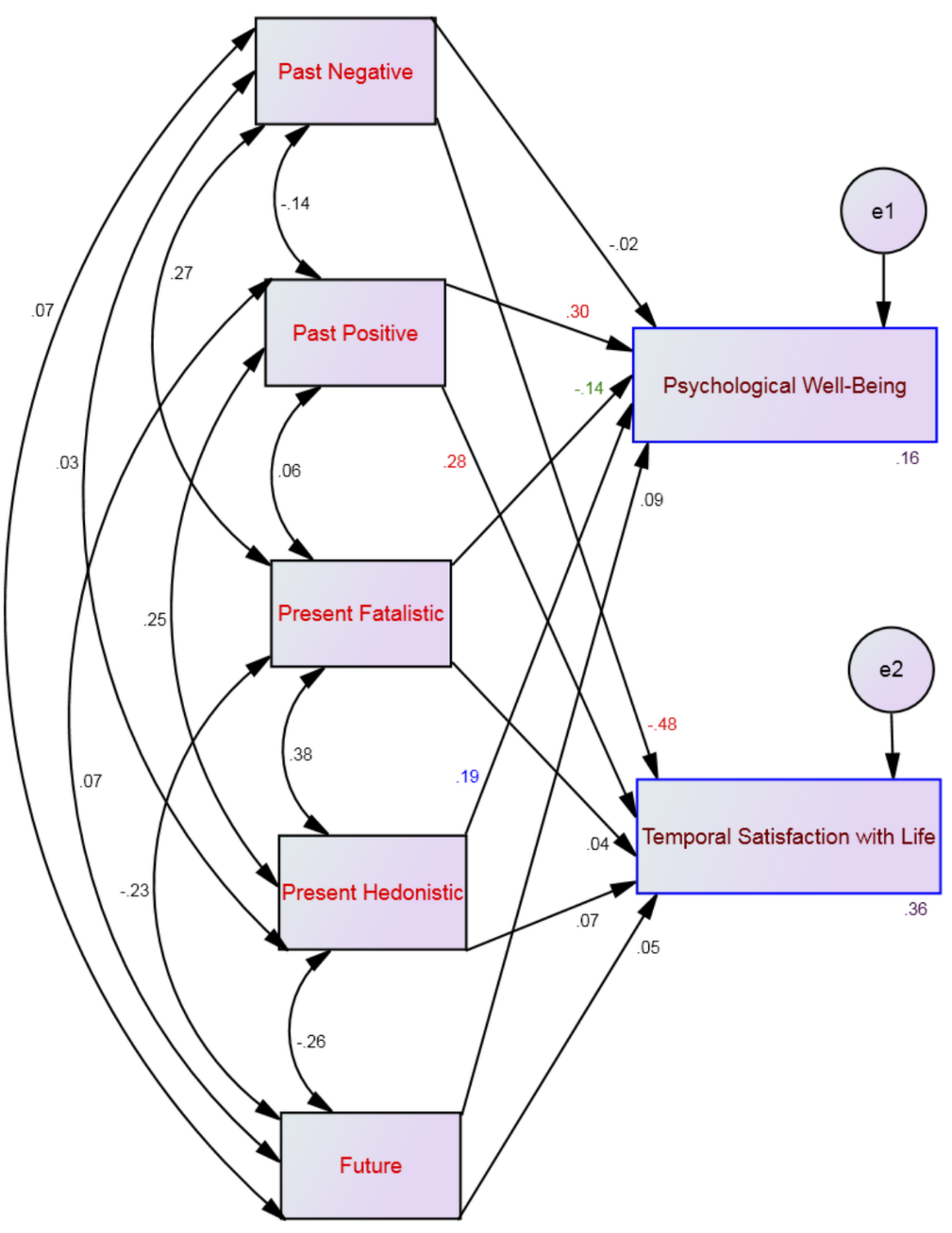




\section{6}

Figure 6

Differences (black arrows) found between individuals with affective profiles that are at their extremes of the model: self-destructive versus self-fulfilling (low-high positive affect, high-low negative affect) and low affective versus high affective (low-high positive affect, low-high negative affect). Differences (grey arrows) found when individuals were matched in one affective dimension, and differed in the other (i.e., within differences): self-destructive versus high affective (matching: high-high negative affect, differing: low-high positive affect), selfdestructive versus low affective (matching: low-low positive affect, differing: high-low negative affect), high affective versus self-fulfilling (matching: high-high positive affect, differing: high-low negative affect), and low affective versus self-fulfilling (matching: low-low negative affect, differing: low- high positive affect). Note. Reprinted with permission from Well-Being and Human Performance Sweden AB. 


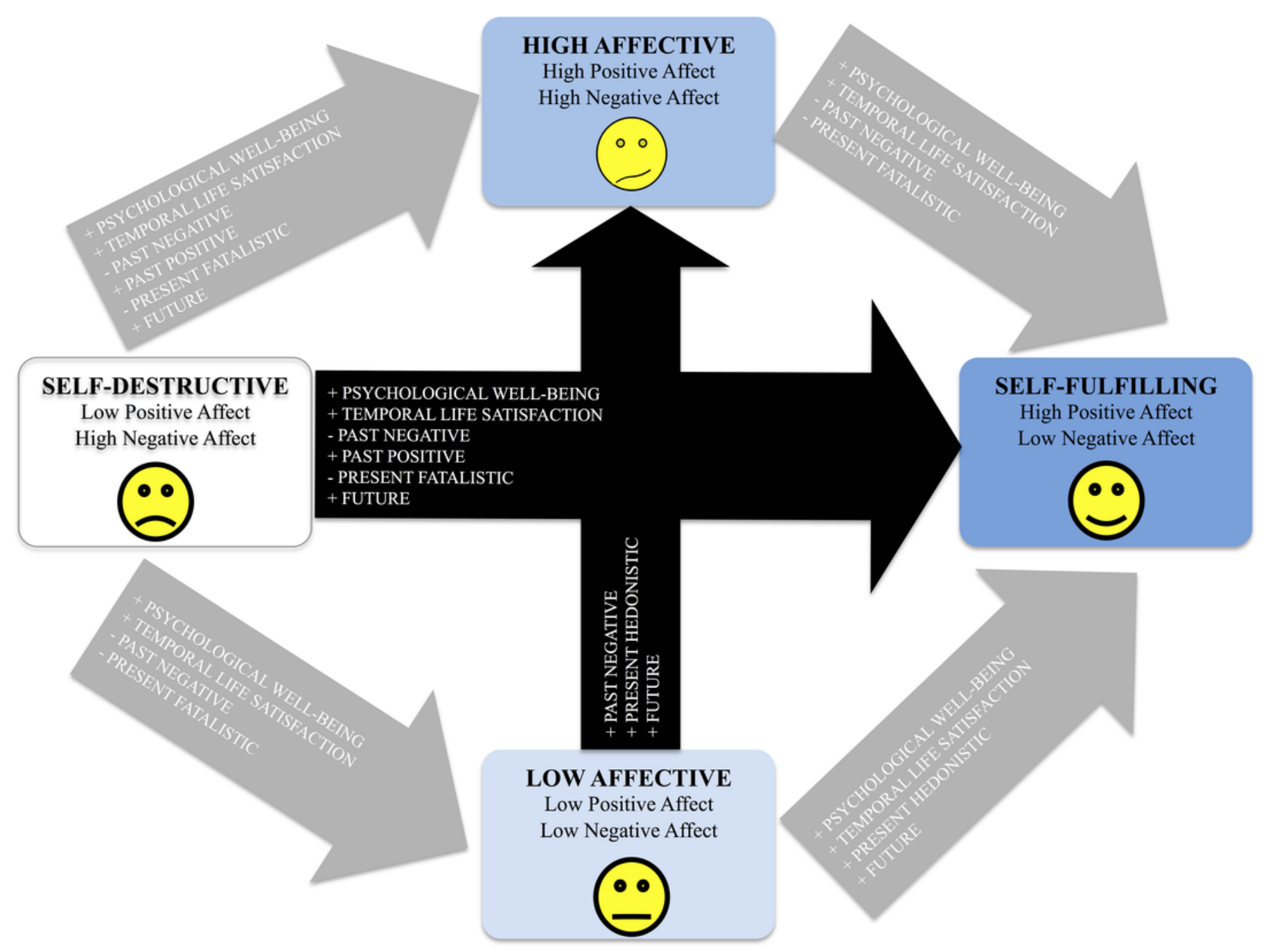

